\title{
傾斜壓延に關する研究 (I)
}

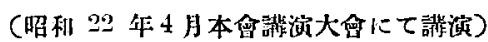

SIIUDY ON THE OBLIQUE ROLLING (I) 池 島 俊 雄*

Toshio Ikeshima

Synopsis: -

The analysis of the piercing mechanism of Mannesmann type piercing machine-the most important application of the oblique rolling-was projected from various experiments.

This report contains the results of experiments on the axial slip between main rolls-oblique rolls and rolled billet and on the power consumption in piercing. The results obtained are as follows:

1. The axial slip is higher than the case of ordiuary rolling.

2. Power consumption per ton of pierced billet $\mathrm{A} / \mathrm{W}$ ( $\mathrm{KWH} /$ ton) is proportional to the deformation degree of piercing $\varphi \mathrm{rm}$, i. d.

$$
\mathrm{A} / \mathrm{W}=17 . \varphi \mathrm{rm}
$$

3. Ideal piercing work is nearly $15 \%$ of real piercing power consumption of the driving motor.

\section{I. 緒言}

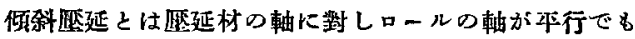

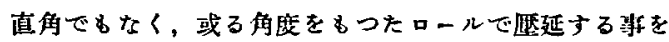
意味するが，その重要な盟用例としてはマンネスマン穿 孔機改どステイーフェル穿孔機がある。この報些ではこ れら鋼管を製喈するのに大切な役割をする穿孔機に於け る穿孔現象を倾斜摭延として取上げ，その理論と宽際上 の問題を研究した結果を迅へろ。この穿孔現象は非常に 複雜で本報はその解析の第一步に過ぎない事を御爰りし $\zeta \neq 0$ ?

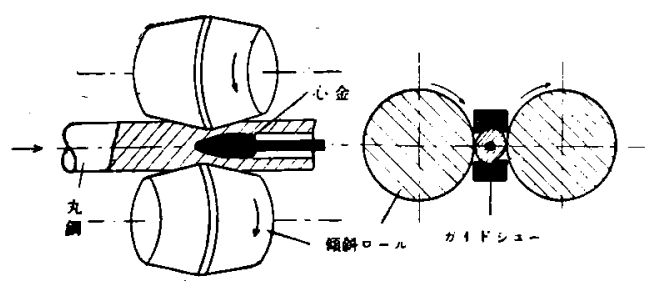

第 1 凅 マンネスマン稊孔機

マンネスマン穿孔機は籍 1 圆に示すゅ 5 K2 箇の倾斜 ロールとブラッグと2䇢のがイドシューと稱する工具か ら成りだつている．ロールの面轉により厢延材は而轉及

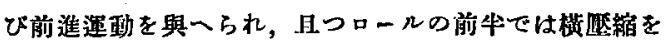

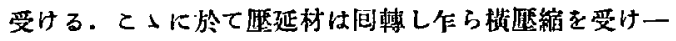

てれを拯み作用 (Friemelung) と稱するーその中心に 孔を生ずるに至る。この理論については第 3 報に逃でる 像定である．较いてロールの啳牛ではロールプラッグ 改びがィドシューの共同作用で孔を掂大し，孔の內面を 滑らかにし，更に肉厚を淢少して中空の素管を作るので， ある、とのゅ5な仕可が 1 间のパスで行注れる上にての 穿孔現象は次に示す多くの setting の因子によつて影譬 される。

1. 堲 延 材

穿孔前の直徑 $\mathrm{d}_{0}$, 穿孔啳の外徑 $\mathrm{d}_{2}$, 內徑 $\mathrm{d}_{2}$.

2. 倾科口ール

直徑 $\mathrm{D}_{1}$ (最大部分), 倾斜角 $\theta$, 入口角 $\varphi_{0}$ ，出口角

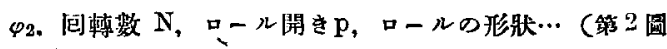
照)

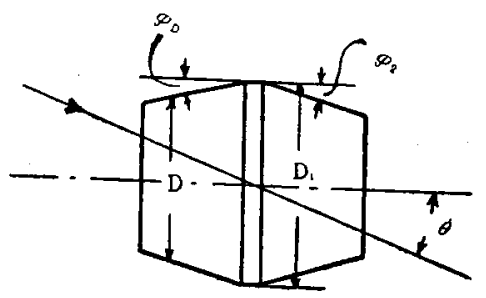

第2 圆倾科口-ル

* 新扶桑企愿工菜株式會社銅管製造所 


\section{3. プ シ グ}

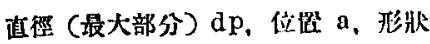

4. ガイトシニー

ガイドシュー間きq、形將

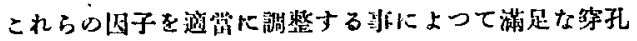
作業が行はれるのであるが，あさりに因子が多いため湖

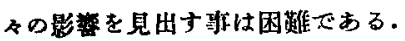

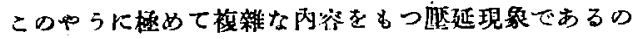

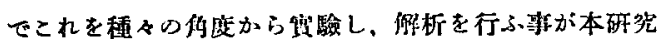
の目的である. 舒 1 報に於ては宾際の等孔機に於て穿孔

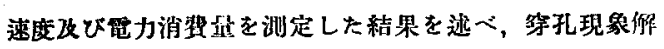
析の資料としゃうとするるのである。

\section{II. 惯驗を行つた穿孔機}

寞嚚は次の場合に就て行つた。

\section{1. 電動 杫}

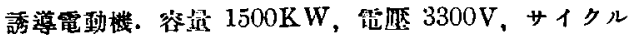
60 , 面䉓数 294 r. p. m.

g. $-ル$

直徨約 $900 \mathrm{~mm}$, 出入口保 $4 \cdot 5^{\circ}, 5 \cdot 5^{\circ}$ 改 $6.5^{\circ}$ 倾斜 角 $3 \sim 12^{\circ}$, 回轉数 80 r. p. m.

3. 穿孔可能を好銅寸法 直湮 $85 \sim 230 \mathrm{~mm}$

\section{II. 穿孔速度について}

\section{(1) 穿孔速度の理諭}

ロールの円周速度の同延材の軸方向の成分 Veal は次 式で表はされる。

Vcal $\fallingdotseq \pi \mathrm{D} \mathrm{N} \operatorname{Sin} \theta$

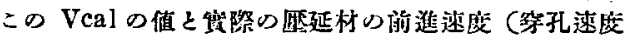
そ同一の意沬) Vの值との篮が汇りとなる。第3 圆に示す 上5に Vealの值は摩延材の軸に沿つて變化している.

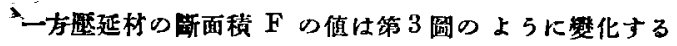

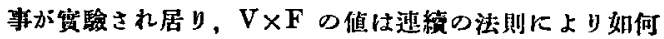
なる點でも一定でなければならぬからVの值は第 3 圆 $\mathrm{Va}$ スはVbの上5になるであら5。この Va Z ZびVb

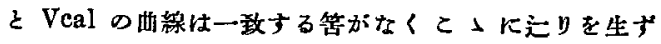
ろ.こて Va 曲線は常にロールの方が早く可轉し， Vbはロール出口附近で迩延枋の方が先進する場合を 示子.上記の理由の外に普通の板, 梅の媪延と遠つてプ ラッグ及びガイドシニーの磨擦抵抗があるため包り捍 加与る. .

（2）穿孔速度に及活す加工度の影留

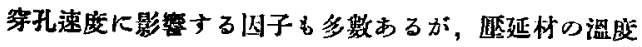

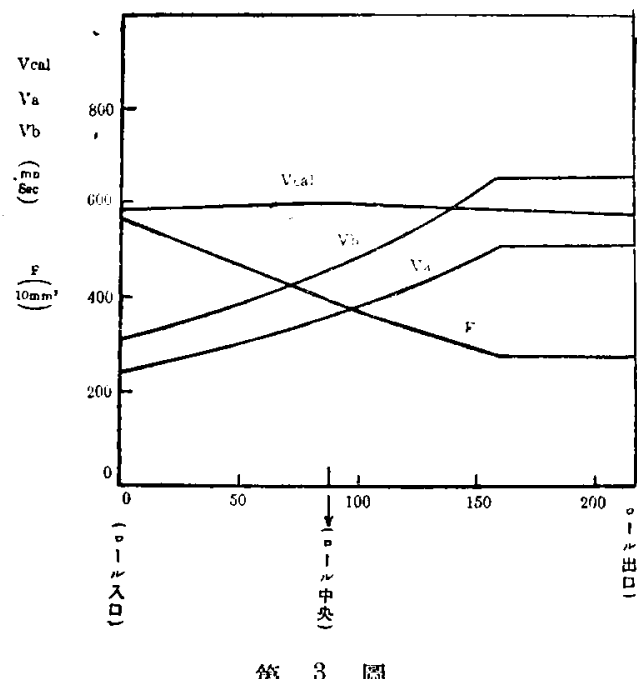

穿孔中に於る正延枋軸方向のロール円同速度と 整延材の速度已の比洓り I 例

$\mathrm{D}_{1}=960 \mathrm{~mm}, \varphi_{0}=\varsigma_{2}=5.5^{\circ}$

$\theta=8.50 \mathrm{~d}_{0}=85 \mathrm{~mm}, \mathrm{~d}_{2}=93 \mathrm{~mm}$

$\mathrm{d}_{2}{ }^{\prime}=71 \cdot 5 \mathrm{~mm}$

阷延材の軸方向の長さ $(\mathrm{mm})$

(ロールと茞延材との接觸開始點を 0 とす)

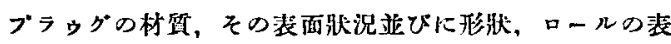

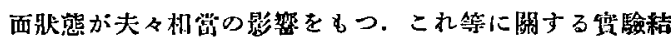
果については省咯し加工度の影繁について逃くる. 加工

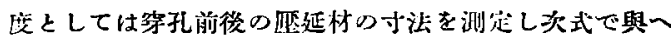
られる $\varphi \mathrm{rm}$ を探用したり。 あるからである。

$$
\begin{aligned}
\varphi \mathrm{rm} & =-\frac{1}{2}\left(\log \frac{\mathrm{F}_{0}}{\mathrm{~F}^{-}} \frac{\mathbf{F}_{1}}{\mathbf{F}} \log \frac{\mathbf{F}_{1}}{\mathrm{f}}\right. \\
& \left.+\log \frac{\mathrm{f}}{\mathrm{F}}\right) \quad \ldots \ldots \ldots \ldots \ldots \ldots \ldots \ldots \ldots \ldots \ldots \ldots \ldots \ldots \ldots
\end{aligned}
$$

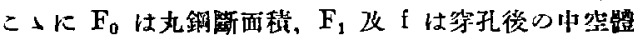

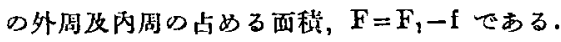

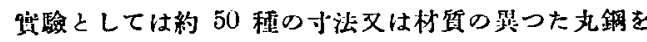

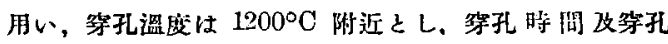

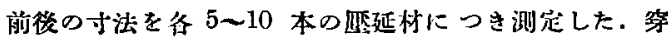
孔時閒をてとするとロールの入口及出口に於る穿孔这度 $V_{0}$ 及 $V_{2}$ は次式で表はされる。

$$
\mathrm{V}_{0}=\mathrm{l}_{0} / \tau \cdots \cdots \cdots(3), \quad \mathrm{V}_{2}=\mathrm{l}_{2} / \tau \text {. }
$$

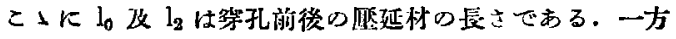
ロールの入口及出口に於けるロール円闌速㛺の国延材軸 方向の成分 $V_{0}^{\prime}$ 及 $V_{2}^{\prime}$ は (1) 武で與一ら机る故にそ

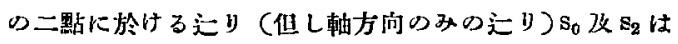


夾の式て舆いられる。

$$
s_{0}=1-\begin{aligned}
& \mathrm{V}_{\mathrm{G}^{\prime}}{ }^{\prime} \\
& \mathrm{V}_{0}
\end{aligned} \cdots \cdots \cdots(5) \mathrm{s}_{2}=1-\mathrm{V}_{2}^{\prime}
$$

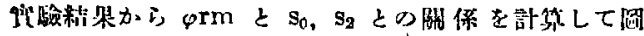

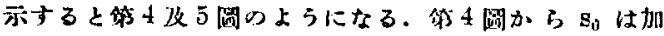

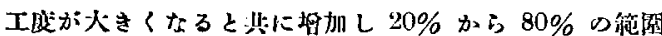

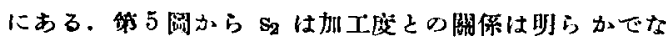

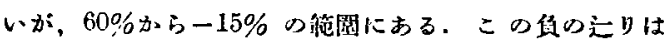

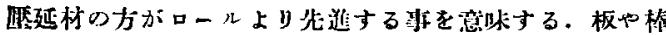

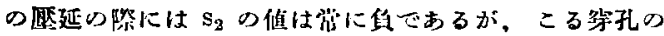
溃合には前進方向一の抵抗が火きいので少数の例を除く と正になつている.この般驗は䄪 6 ケ月に五つて行つた

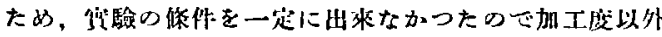

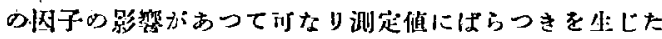

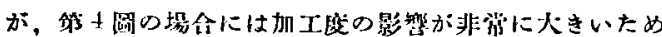

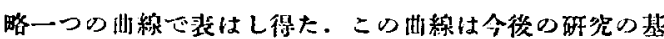
礎䜤料として使刀する。

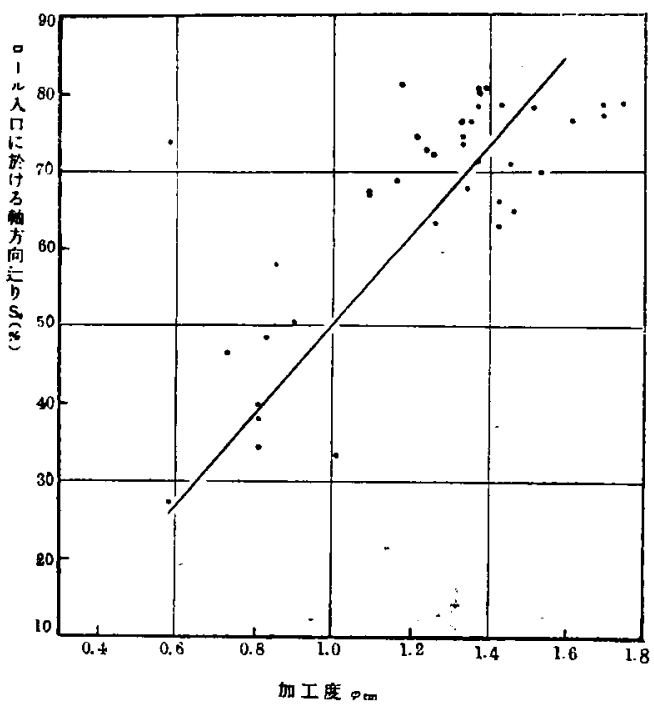

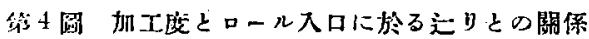

\section{IV.r霓力消費量について}

(1) 穿孔に贸する訨牙

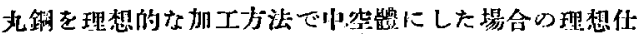
Jf Aid は次式で與へられる。

Aid $=V \cdot \kappa^{\mathrm{f}} \cdot \omega_{\mathrm{rm}}$

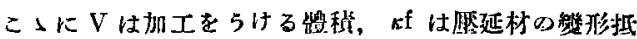

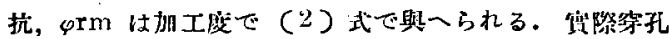

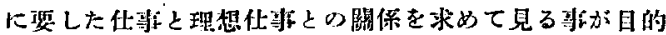
である.（7）武に於ける $\mathrm{kf}$ の值については第 6 圆に

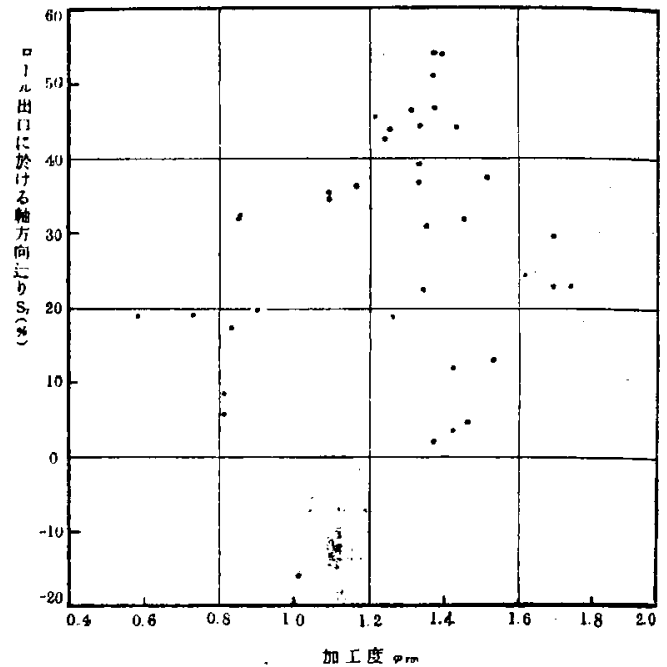

解万阔加工设とロール出口に於る过りとの關㮇

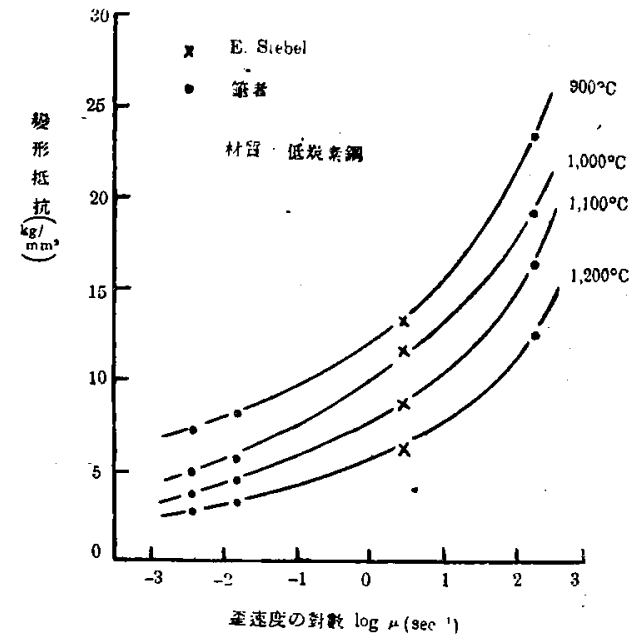

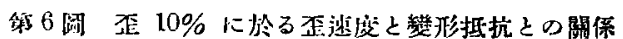

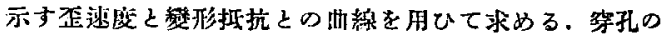

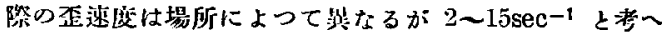
られるので $1200^{\circ} \mathrm{C}$ に於ては $\kappa \mathrm{f}=6 \sim 8 \kappa \mathrm{g} / \mathrm{mm}^{2}$ とをる 手にする。

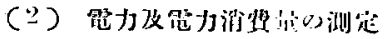

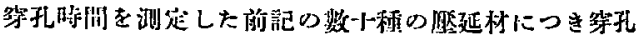

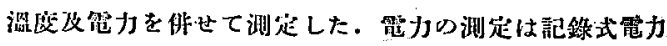

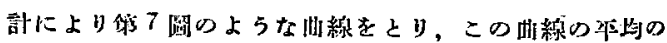

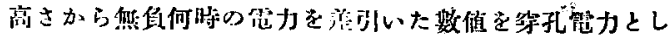

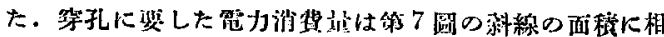


常する琶力とした。

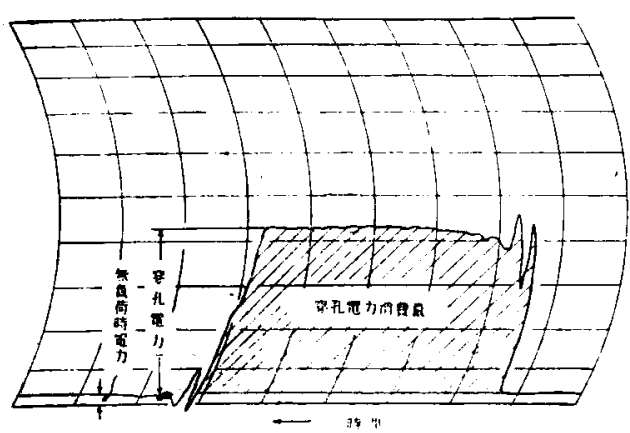

第7 圆穿孔中に於る洔间一雷力明綵

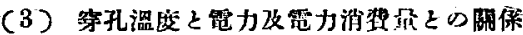

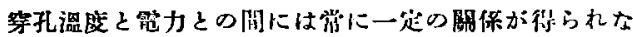

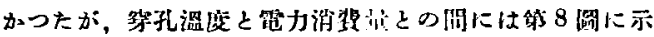

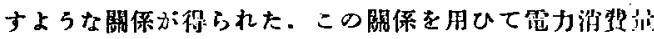

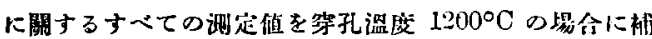
正する斀とした。

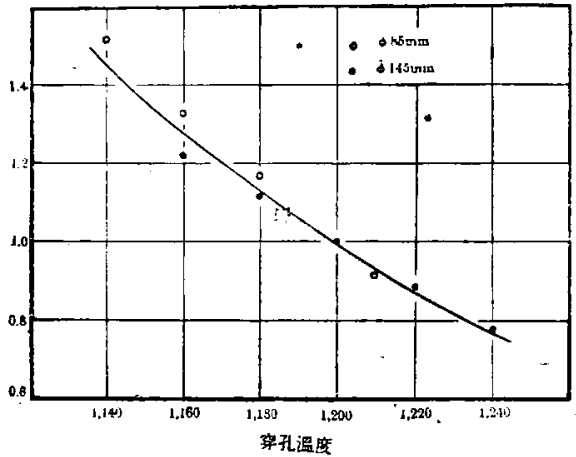

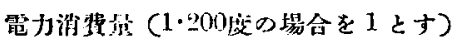

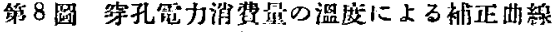

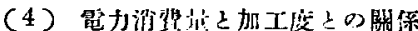

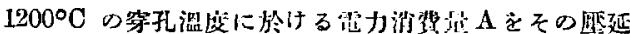
材の重量Wて教つた值 $\mathrm{A} / \mathrm{W}$ と加工废

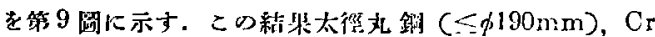

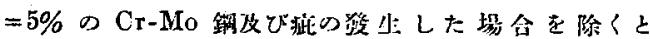

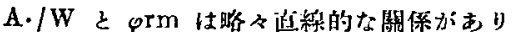

$$
\mathbf{A}=17 \times \mathbf{W} \cdot \varphi \mathrm{rm}
$$

となる，A の單位は $\mathrm{KWH}$ Ｗは tonである。

(5) 倾斜腰延心加工放笔

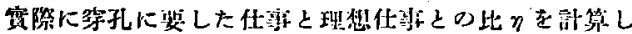
て見ると

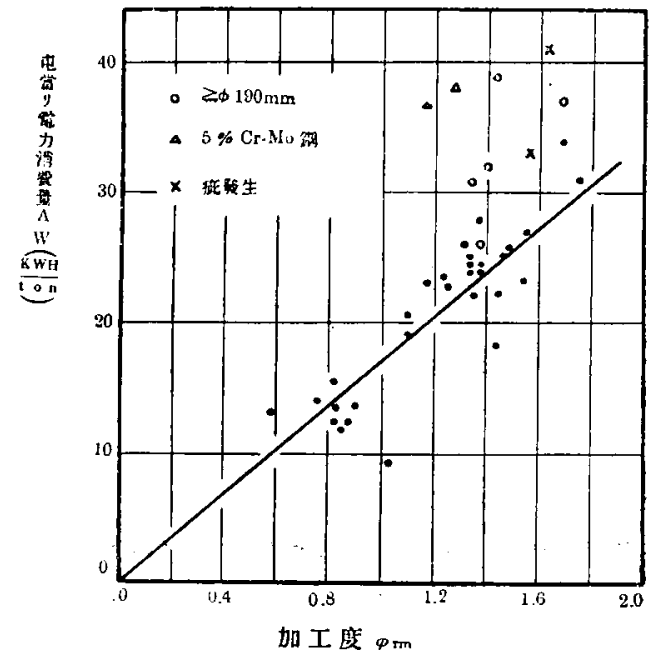

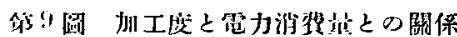

$$
\begin{aligned}
\eta= & \frac{\operatorname{Aid}}{A}=\frac{\mathrm{V} \cdot \kappa \mathrm{f} \cdot \varphi \mathrm{rm}}{W \cdot 17 \cdot \varphi \mathrm{rm}} \\
& =\frac{\kappa \mathrm{f}\left(\mathrm{\kappa g} / \mathrm{mm}^{2}\right)}{48 \cdot 6\left(\mathrm{~kg} / \mathrm{mm}^{2}\right)} \cdots \cdots
\end{aligned}
$$

となる.そこで征逝の近り $\kappa \mathrm{f}=6 \sim 8 \mathrm{~kg} / \mathrm{mm}^{2}$ とすると

$$
\eta=.12 \cdot 3 \sim 16 \cdot 5 \%
$$

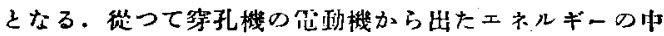
粎 $15 \%$ が琶想訨打に相霜する打となる。この殘りの仕 牙は次の可に消韯されたと考へら礼る。

A. 外部訨 괸

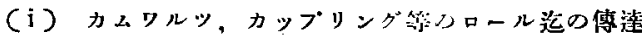
部分に於ける損尤

(ii） ロール軸愛部分心於ける損上

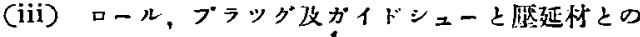
閉の度擦椇火

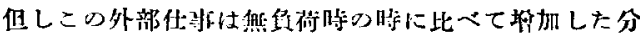
のみである。

B. 队部仕易的

(i) 厚延中，外徑を一废娍少した後䏚び復火するの

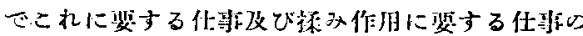
一部

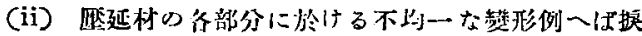
札等に紧する仩到

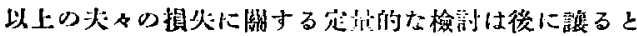

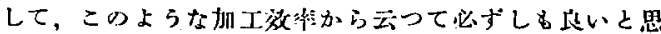

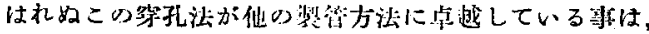

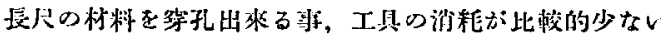




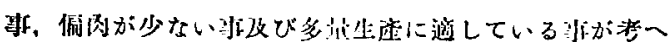
ら机る。

\section{V. 繀語}

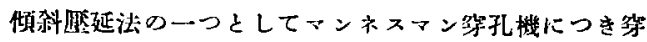

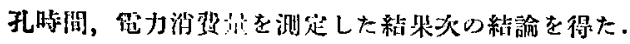

(1) ロールの入口に於てはロールの方が聇延材上り

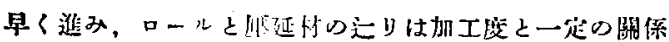
にある。

(さロールの出口に於ては少数の例を除いてはゃは

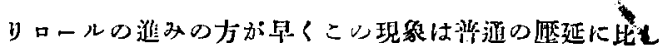

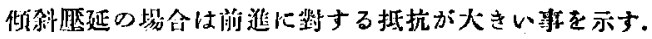

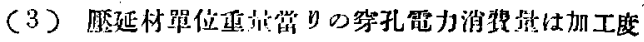

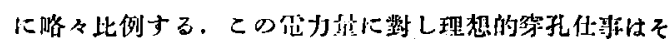

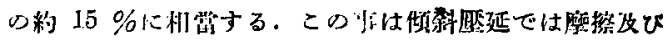

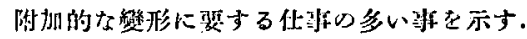

(昭和 25 年 4 月寄稿)

齐 解

I) É. Siebel und E. Fangneier, Mitt K.-W.Inst. Eisenforsch. I3 (1931) \&. 29

\title{
鋼に於ける炭化物の球狀化に就て (II)
}

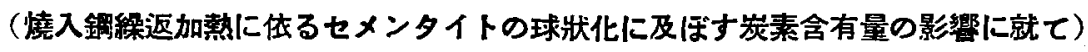

\author{
佳 藤 知 雄*矢帛悅 次 郎* \\ ON SPHEROIDIZING OF CARBIDE IN S'TEELS (II) \\ (Effect of Carbon Content on the Spheroidizing of Cementite \\ of Quenched Steel by Repeated Heating and Cooling.)

\section{Tomo-o Sato and Etsujiro Yajima}

Synopsis:

Quenched Sweden carbon steels containing about $0 \cdot 1,0 \cdot 3,0 \cdot 5,0 \cdot 7,0 \cdot 9,-1 \cdot 2$ and $1 \cdot 3 \% \mathrm{C}$ were subjected to repeated heating and cooling passing $A_{1}$ point, and the effect of carbon content on the sphercidizing of cementite in those steels was studied.

One cycle of heating and cooling was carried out as follows:

$700^{\circ} \rightarrow 760^{\circ}$, heating $1 \% \mathrm{~min}$, hold at $760^{\circ}$ for $14 \mathrm{~min}$.

$760^{\circ} \rightarrow 700^{\circ}$, cooling $1 \% \mathrm{~min}$, hold at $700^{\circ}$ for $30 \mathrm{~min}$.

This cycle was repeated 1 to 5 times, and after each cycle the rate of spheroidizing of cementite was measured by means of Rockwell hardness tester.

After 3 times of the cycle in Hypo-eutectoid steel and after 5 times of it in Hyper-eutectoid steel the spheroidizing was completed - that is, the lowest constant hardness was obtained. Difference of the quenched structure - if the same steel - does no effect on the final spheroidal structure and its hardness by this heat treatment.

The final hardness of spheroidized steel thus obtained is expressed by following formula:

Rockwell hardness in B scale $=21 \times \mathrm{C} \%+72 \cdot 9$

This hardness is more or less higher than that of the spheroidized one made from the same steel having the lamellar pearlite structure.

\section{I. 緒言}

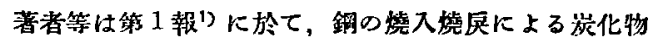

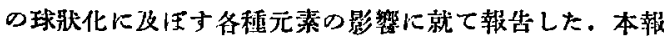

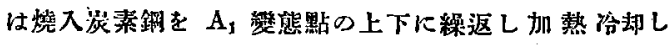
てセメンタイトの球狀化を行5場合，球枵化に及改す銅

\footnotetext{
* 束北大學工學部金鹰工學科
} 